\title{
A revitalização da política de livro didático no Brasil: regular e avaliar para qualificar
}

\author{
The revitalization of the school textbook policy in Brazil: \\ making rules and evaluating to qualify
}

Fernando Garcez ${ }^{1}$

\section{Resumo:}

O trabalho investiga a política brasileira do livro didático, materializada no Programa Nacional de Livro Didático, e objetiva apreender o quê, como e as razões que conduziram à implementação e operacionalização de um determinado modelo de regulação. Aprovado em 1985, esse Programa sofre uma guinada, em 1995, no bojo da reforma do Estado brasileiro, mas também por fatores intrínsecos entre forças econômicas e sujeitos sociais. Confluente ao momento histórico foi impresso a ele um sentido de regulação que atende interesses diversos, ainda que em magnitudes distintas.

Palavras-chave: Política Educacional; Livro didático; Regulação.

\begin{abstract}
:
This paper investigates the Brazilian textbook policy, embodied in the National Textbook Program, and aims to learn what, how and the reasons that led to the implementation and operation of a particular model of regulation. Approved in 1985, this program suffers a shift in 1995 in the wake of the reform of the Brazilian state, but also by intrinsic forces between economic and social subjects. Confluent historical moment it was printed a sense of regulation that serves diverse interests, albeit in different magnitudes.

Keywords: Educational Policy; Textbooks; regulation.
\end{abstract}


Em 1985, em meio à redemocratização no Brasil e os problemas educacionais, alterou-se a forma de conduzir e operacionalizar a política de livro didático, que resultou na aprovação do Programa Nacional do Livro Didático (PNLD) instituído pelo Decreto n. 91.542, de 19 de agosto de 1985. Com ele, findou o processo de coedição - que foi um convênio entre a instância federal e os entes estaduais para produção dos livros didáticos - mas se manteve praticamente omisso quanto à avaliação das obras. Nesse sentido, o ano de 1995 representou, na história da produção e consumo do livro didático no Brasil, a retomada acurada de sua regulação no campo político, econômico e pedagógico com tensões e aproximações em torno de um direito social reclamado por estudantes, família e professores. As feições que o livro didático assume no contexto social oscilam conforme as diferentes perspectivas sobre ele: no campo político, difusor da ideologia liberal (mas não exclusivamente); no campo educacional, em um contexto de precário funcionamento do sistema educacional, ele exerce uma função mister de ordenação e sistematização dos saberes; no campo econômico, fonte de faturamento e lucros para os grupos editoriais.

Dessa forma, as diferentes funções que o livro didático exerce e que são efetivamente significativas para cada um dos grupos interessados, embora os interesses entre eles possam ser divergentes, tornou-o alvo de disputas quanto ao conteúdo, metodologia, ideologia e formato editorial ao longo da história, e ainda o é. Para nós, sua importância delineia-se a partir das ações do Estado compreendido como articulação recíproca entre sociedade política e sociedade civil, daí, o intento de apreender o quê, como e as razões que conduziram à implementação e operacionalização de um determinado modelo de regulação sobre a política de livro didático.

Para tanto, elencamos dois tipos de fontes: a) documentais: legislação, documentos oficiais e pesquisas; e b) o depoimento de docentes. O trabalho pauta-se num enfoque histórico que intenta captar os dados empíricos e os situam no bojo do contexto social. Com um olhar dialético, almeja-se articular alguns aspectos locais da escola com os nacionais expressos pelo jogo de forças que sintetizam as políticas públicas. Nesse sentido, a perspectiva histórica de Gramsci (1995) nos auxilia com os conceitos de Estado ampliado e hegemonia, além de assinalar a importância das lutas de classe e o próprio papel dos trabalhadores na construção da história. ***

A ascensão à presidência da República por Fernando Henrique Cardoso (1995-2002) significou uma inclinação acentuada para a adoção de medidas de corte neoliberal ${ }^{2}$ com notáveis implicações no campo da política para o livro didático. Seu governo foi marcado pela realização da Reforma Gerencial de Estado, coordenada pelo então Ministro da Administração Federal e Reforma do Estado (1995-1998) Luiz Carlos Bresser-Pereira. As razões para ser operacionalizado e os pilares econômicos e políticos que sustentaram suas ações estão sintetizadas no Plano Diretor da Reforma do Estado (doravante Plano Diretor) elaborado pelo referido Ministério (BRASIL, 1995).

A razão para a implementação do Plano Diretor apresentada por Fernando Henrique Cardoso foi "a crise brasileira da última década foi também uma crise do Estado" (BRASIL, 1995, p. 6). Este tivera ampliado demasiadamente, na ótica neoliberal, suas funções para o campo produtivo e desencadeado o desequilíbrio fiscal e a inflação. Assim, sua reforma tornou-se indispensável sob o corolário do crescimento sustentado da economia e a correção das desigualdades sociais e regionais. Para esse governo, os maiores problemas decorrentes do Estado e que definiram sua crise foram três:

1) como uma crise fiscal, caracterizada pela crescente perda do crédito por parte do Estado e pela poupança pública que se torna negativa; (2) 0 esgotamento da estratégia estatizante de intervenção do Estado, a qual se reveste de várias formas: 0 Estado do bem-estar social nos países desenvolvidos, a estratégia de substituição de importações no terceiro mundo, e o estatismo nos países comunistas; e (3) a superação da forma de administrar o Estado, isto é, a superação da administração pública burocrática (BRASIL, 1995, p. 10-11).

2 Embora não seja possível estabelecer um único fato que reluza a perspectiva neoliberal no Brasil devido à processualidade em que se desenvolve a história, podemos demarcar que passa a materializar-se (ou encruecer) no governo de Fernando Collor de Mello (1990-1992) e tendo continuidade com Itamar Franco (1993-1994). Lembrando que neste Fernando Henrique Cardoso foi Ministro da Fazenda e considerado o maior responsável por conceber o Plano Real. 
A Reforma do Estado, apesar de se dirigir à esfera federal e não às estaduais e municipais, puderam por estas serem incorporadas. Isso indica também a magnitude da reforma, que se pretendia ampla, mas com alvos específicos. O seu contexto de realização entendido na redefinição das funções do Estado faz com que "deixe de ser o responsável direto pelo desenvolvimento econômico e social pela via da produção de bens e serviços, para fortalecer-se na função de promotor e regulador desse desenvolvimento" (BRASIL, 1995, p. 12). Essa redefinição foi fulcral na produção bens e no setor de serviços, alvos fundamentais para obtenção de mais-valia, não devendo, portanto, ser locus de intervenção do aparelho estatal. Entretanto, apesar de ser esse o ideário em voga, não era possível desconsiderar as crescentes demandas sociais incitantes do Estado "que se viu obrigado a responder, até por uma questão de sobrevivência, e renunciou à sua posição equidistante de árbitro social para tornar-se francamente interventor" (PEREIRA, 2008, p. 30).

Essa conjuntura em que se situava (situa) o Estado brasileiro contribui para compreender as ações e medidas selecionadas para revitalizar a política para o livro didático. Vamos notar que para efetivar o plano de reestruturação foi necessário, inclusive, se aproximar de interesses sociais, porém de forma cautelosa. $E$ isso representa não somente uma forma ardilosa de alcançar os próprios fins economicistas, mas sim uma conquista das classes sociais desfavorecidas historicamente.

O quadro da política do livro didático começou a mudar, em grande parte, por motivos intrínsecos e pedagógicos, evidenciados pelas pesquisas realizadas por Grupos de Trabalho instituídos pela Fundação de Apoio ao Estudante (FAE), em 1993, para avaliar as obras didáticas de português, matemática, estudos sociais e ciências utilizadas nas $1^{a}$ a $4^{a}$ séries; trabalho intitulado Definição de critérios para avaliação dos livros didáticos (BRASIL, 1994). Neste estudo foram analisados os principais livros didáticos adquiridos pelo governo no ano de 1991 e que correspondiam a 94\% das compras governamentais. Um dos resultados apresentados foi de que os livros didáticos expressavam a visão da escola e do papel do professor como:

Repassador de informações estratificadas, obsoletas e errôneas, imune à concepção de que um mundo de mudanças vertiginosas de valores, da ciência e da tecnologia exige, acima de tudo, indivíduos com capacidade de resolver problemas novos para sobreviver, portanto, de pensá-los.

0 que aprofunda a gravidade do problema, encobrindo tais conteúdos retrógrados, é que boa parte de quem produz o livro didático soube aproveitar as tecnologias mais avançadas de marketing. Conhecedora das condições de trabalho dos professores da rede de ensino, mal pagos, com dificuldades de se atualizarem e, muito mais, de prepararem as aulas e exercícios e de se capacitarem para avaliar, escolher e indicar o livro didático (BRASIL, 1994, p. 103).

Esse estudo culminou em quatro proposições para serem executas: a) estabelecimento pelo MEC de um programa mínimo obrigatório de âmbito nacional, com os objetivos, conteúdos e orientação pedagógica em todas as disciplinas que constituem o currículo do $1^{\circ} \mathrm{grau}$; b) instituição na FAE de uma instância de avaliação do livro didático; c) campanha sistemática de divulgação dos resultados da avaliação do livro didático; e d) incentivo a grupos qualificados para a produção de livros didáticos (BRASIL, 1994, p. 103-104).

As propostas desdobraram-se, entre outras ações, na elaboração dos Parâmetros Curriculares Nacionais/ PCNs (1997), cumprindo o item (a). E também ao estabelecimento da avaliação dos livros didáticos, em 1996, e a consequente publicação do Guia do Livro Didático ${ }^{3}$ com uma resenha das obras analisadas, itens (b) e (c). Quanto ao item (d) se por grupos qualificados entende-se empresas editoriais privadas, então cumpriuse. Contudo, se os entendermos como grupos de instância pública e articulados à comunidade escolar desvinculados da lógica do mercado, então não tivemos a efetivação do item (d), pois os grupos não foram criados, prevalecendo, portanto, a lógica de regular o mercado de produção dos materiais didáticos.

Com a instituição da Comissão Avaliadora, a qualidade dos livros inscritos em 1997 no PNLD foi verificada por meio de uma triagem técnica que objetivava excluir livros com defeitos físicos e materiais de baixa qualidade,

30 Guia é um catálogo com uma apresentação das obras submetidas à avaliação e aceitas para que os professores da educação básica possam selecionar aquela condizente com as suas condições culturais e pedagógicas 
bem como pela avaliação pedagógica que verificou (i) correção e adequação conceitual e das informações básicas, (ii) coerência e pertinência metodológicas e (iii) preceitos éticos. Para Miranda e Luca (2004, p. 128) "a instituição de uma cultura avaliativa, num contexto político democrático, acabou por desencadear poderosos mecanismos de reajustamento e adaptação no mercado editorial”. Nesse sentido, essa avaliação possibilitou melhorar a qualidade de algumas obras didáticas tendo em vista que as editoras passaram a atender aos critérios estabelecidos, bem como demarcou "referências de qualidade para o livro didático; [retirou] uma série considerável de obras com graves problemas de conteúdo e concepções danosas ao ensino e à aprendizagem; incentivaram debates sobre o tema" (BEZERRA; LUCA, 2006). Esse desdobramento proporcionou,

Ainda que o processo de aperfeiçoamento dos critérios e procedimentos de avaliação seja bastante recente, a relação de continuidade dessa política por quase uma década teve efeitos incontestáveis na forma e no conteúdo do livro didático brasileiro. Na área de História é patente a transformação: de um cenário marcado pelo predomínio de obras que veiculavam, de modo explícito ou implícito, todo tipo de estereótipo e/ou preconceitos, para um quadro em que predominam cuidados evidentes, por parte de autores e editores, em relação aos critérios de exclusão de uma obra didática (MIRANDA; LUCA, 2004, p. 127).

Com a Comissão Avaliadora, o Estado retoma e revitaliza sua ação regulatória ao estabelecer a vigilância e regulamentação sobre a produção do livro didático. Entendemos que as avaliações das obras vieram e, de certa forma, cumpriram o objetivo de melhorar e qualificar os livros didáticos destinados aos professores, ou seja, uma regulação para assegurar o direito à informação e ao conhecimento e que atende prerrogativas públicas e sociais da educação. Entretanto, tais avaliações não são isentas de polêmicas e conflitos, por exemplo, em 2009, a Associação Brasileira de Autores de Livros Educacionais (Abrale) lança uma nota com uma série de considerações sobre os programas governamentais do livro didático. São críticas dirigidas com o intuito de aprimorar a qualidade e aumentar a transparência do processo avaliativo das obras. Neste comunicado, apresenta que os pareceres da Comissão do PNLD geraram exclusão de coleções didáticas contendo "críticas inadequadas, critérios confusos, erros evidentes e descuidos inaceitáveis"” (ABRALE, 2009, p. 3).

Por outro lado, a regulação não se dirige apenas à iniciativa privada, se estende, concomitantemente, para o controle dos conteúdos, metodologias, imagens, fotografias e formatos dos livros, bem como sobre o processo de escolha por seus destinatários. Assim, revigorou-se a atuação do Estado que adentra nos meandros da cultura institucional escolar e logra difundir determinado pensamento pedagógico e conformar as práticas pedagógicas. Para influenciar a cultura escolar, a política do livro didático se articulou com os PCNs como forma de regulação do currículo. Como expôs o Ministro da Educação, Paulo Renato Souza (1995-2002):

Ao final, prevaleceu a orientação de elaborar um parâmetro curricular nacional ou um referencial curricular nacional para evitar justamente os entraves legais; um parâmetro ou referencial não é obrigatório nem fere a autonomia de Estados e Municípios. De todo o modo, se o parâmetro ou o referencial são de boa qualidade, acabam se impondo. Essa tendência no Brasil foi reforçada e acelerada pelo fato de 0 Ministério ser um grande comprador de livros didáticos e ter introduzido, a partir de 1996, a avaliação desses livros com base precisamente nesses parâmetros (SOUZA, 2005, p. 123).

A compreensão de Barroso (2005) de que na educação acontece uma regulação das regulações corrobora para entender que a homogeneidade ou a aglutinação do currículo é feita não nos pormenores de cada conteúdo, como no início do século XX. Elas ocorrem nos fundamentos políticos e princípios balizadores como os da empregabilidade e no desenvolvimento das competências, bem como pelas chamadas pedagogias do aprender a aprender. Dessa forma, as razões para estabelecer a regulação da política do livro didático ligamse tanto ao anseio pelo aprimoramento dos conhecimentos e saberes a ser difundido quanto pelo ensejo em difundir um específico ideário educacional confluente com a reestruturação do Estado nacional à época em

4 Apenas para ilustrar o que considera inadequado, o documento da Abrale apresenta a seguinte situação ocorrida: "Uma obra é criticada por ter pouca variedade de textos, mas, na tabela fornecida no Guia pelos próprios avaliadores, verifica-se que muitas outras obras, com menor variedade, não sofreram tal crítica; aliás, a obra em questão só era superada nesse quesito por uma única outra! Nessa mesma obra, o parecerista considera inadequados para leitura das crianças os textos das páginas iniciais (ficha catalográfica, sumário, nome e endereço da editora, etc.), textos obrigatórios segundo a estrutura editorial definida no anexo I do edital. É inacreditável!” (ABRALE, 2009, p. 3). 
construção. Soma-se a isso o fato do Brasil fomentar uma educação pública como privilégio, e que favoreceu a expansão da educação básica com professores formados precariamente, sendo o livro didático uma ferramenta para superar parte desse problema.

\section{Sobre regulação e sua repercussão nos atores escolares}

A partir do exposto realça-se que o livro didático representa um direito e conquista dos trabalhadores e, também, fonte de acumulação de capital para a indústria editorial. E o PNLD pode ser o próprio modo de regulação à medida que define as bases de governança com ordenamentos que supõem uma concepção de organização social, política e econômica, a partir da qual se definem responsabilidades e competências do Estado, do mercado e da sociedade, e tendem, também, a desencadear processos de ressocialização. Nesse sentido, manifesta-se um caráter objetivo da regulação, o de coordenar e estabelecer parâmetros adequados para o funcionamento da política ou da ação do Estado.

Como assinala Barroso (2005), a concepção e a forma de pôr em prática uma regulação se articula com os pressupostos da acepção e reestruturação do Estado. Ao revisar o termo regulação, podemos iniciar com sua elaboração mais comum, como em Ferreira (2010), de "ato ou efeito de regular (se)" que se desdobrasse em: 1. "que é ou que age conforme as regras, as normas, as leis, as praxes"; e, 2. "esclarecer e facilitar por meio de disposições (a execução da lei); regulamentar". De início, pode-se perceber a polissemia do termo, que se refere tanto ao como regular que é a priori quanto o efeito do regular, a posteriori, identificado em contexto concreto. Para tornar mais complexo o termo, destacar-se-á que a regulação a priori materializa-se por regras, normas e procedimentos tão diversos quanto os princípios e fundamentos que balizam a sua construção e, por conseguinte, inúmeros desencadeamentos da regulação. E, além disso, podemos situar o seu processo, ou seja, como são estabelecidos tanto a construção da regulação quanto as ações humanas que a materializam.

A regulação, em sentido amplo (abstrato), a priori, pode ser entendida como "um processo constitutivo de qualquer sistema e tem por principal função assegurar o equilíbrio, a coerência, mas também a transformação desse mesmo sistema" (BARROSO, 2005, p. 733). Para cumprir sua função, são deliberados consensos, elaboradas regras e ordenamentos que atuam sobre os diversos níveis de um sistema educacional e os sujeitos, demonstrando ser a regulação múltipla e dinâmica e não um processo único, previsível e automático. Concreta e historicamente, a regulação ocorre em meio a disputas, processos constituintes, que conformam as práticas dos sujeitos. Esse processo que define a sua forma: se (i) mais flexível na definição dos processos e rígida na avaliação da eficiência e eficácia dos resultados ou, o seu oposto, (ii) centrada na definição e controle a priori dos procedimentos e relativamente indiferentes às questões da qualidade e eficácia dos resultados, bem como, (iii) ainda de acordo com Barroso (2005, p. 734), se "resulta mais da regulação das regulações, do que do controlo directo da aplicação de uma regra sobre acção dos 'regulados'”.

Nesse sentido, a implementação de uma política pública, no caso o PNLD, significa o imbricamento de diferentes mecanismos em razão do seu amplo alcance. A regulação da educação pelo Estado via PNLD remete à: i) a produção das obras pelas editoras; ii) a apropriação dos materiais didáticos pelo corpo docente. Como já visto, o primeiro aspecto obteve avanço. O segundo aspecto mostra-se mais complexo, visto que a regulação se dá por um misto de persuasão e imposição, pois o livro é disponibilizado para o corpo docente que se vale desse instrumento pedagógico da forma que julgar e considerar mais profícuo no balizamento do processo de ensino e aprendizagem. Dessa forma, torna-se imprescindível uma consonância entre a perspectiva do Estado e a dos professores para que flua a implementação. Para tanto, cabe observar que a política reequipa a prática pedagógica com uma ferramenta, o livro didático que é bem aceito pelos docentes por dispor de textos, imagens e documentos históricos, bem como pela sua sistematização e permitir aos estudantes um acompanhamento mais próximo dos conhecimentos selecionados a serem ensinados, embora também façam ressalvas e críticas. 
Além disso, estabeleceu na sua operacionalização que a escola, mediante a deliberação entre os professores, realize a escolha do livro para trabalhar com os estudantes.

Ao tomarmos a concepção ampliada de Estado proposta por Gramsci, podemos notar que a sociedade civil carrega a capacidade de reler, intervir, negociar, confrontar as normas que são formuladas ainda dentro do Estado em seu âmbito burocrático e de formulação da política. Dessa maneira, nem toda regulação nacional se manifesta como injunção ou constrangimentos, mas também pode fomentar, assegurar ou alavancar as demandas populares e das culturas escolares, e ainda podem ser reconstruídas e modificadas.

Se parece plausível que o Estado aumentou a regulação na educação, outrossim, existem ações e medidas de democratização do poder e de participação nos processos decisórios, ou seja, que ampliam a autorregulação: que leis e normas sejam definidas pelos próprios sujeitos que irão cumprir. Diferentemente da autorregulação sob o invólucro neoliberal, que apregoa a liberdade formal e abstrata, pautada na lógica de mercado e o desmantelo do Estado de bem estar social, no sentido gramsciano, a noção de autorregulação ou autodeterminação incorpora o sentido histórico. Assim, são as ações confluentes às prerrogativas de plena liberdade e responsabilidade que visam à promoção e ao desenvolvimento do ser humano individualmente e do bem estar coletivo. Para tanto, Semeraro (1999) explicita que "o conteúdo econômico-social e a forma ético-política se interpenetram e são orientados à elevação das massas por uma vontade coletiva que nasce de determinadas relações econômicas, como expressão da nova formação humana" (p. 143). Sobressai, dessa maneira, o incentivo à iniciativa e ao desenvolvimento da subjetividade pelo escrutínio das bases reais e combate "às pressões exteriores que visam a condicionar o seu comportamento" (Ibid., p. 153).

Assim, reconhecem-se as limitações da efetivação de processos participativos nesse modelo societal, contudo a esses processos se agrega valor na medida em que contribui para explicitar e desenvolver os componentes essenciais do ser genérico do homem. Trata-se, dessa maneira, de alavancar a democratização (que denota seu sentido de processo, de porvir) e os instrumentos nela subtendidos, como: acesso ao conhecimento, aos saberes mais ricos e desenvolvidos pela humanidade, e criação de espaços para negociação da qualidade da educação. De fato, efetivar um projeto de democratização popular tornou-se tarefa que requer consistência e continuidade nas ações, além de reiterada revisão e aperfeiçoamento de estratégias para sua implementação. Para ter uma dimensão, concordamos com Nogueira quando apresenta um desafio teórico-prático a ser enfrentado pela sociedade e pelos trabalhadores da educação:

Trata-se, aqui, de encontrar meios de pôr em curso a organização e a estabilização de um espaço que seja simultaneamente ocupado pela sociedade civil e regulado pelo Estado, quer dizer, um espaço para ser democraticamente controlado e no qual seja possível fincar as estacas de uma política voltada para o "geral", para a justiça social e a igualdade. A unificação [entre sociedade política e sociedade civil] traz também o desafio de ajustar o Estado, de repô-lo como instituição vocacionada para a coordenação, a regulação, o planejamento (NOGUEIRA, 1998, p. 92).

Do exposto, sobressai a diversidade de regulações na educação pública que é ambivalente: um misto de caráter persuasivo e impositivo. Além disso, o ato de regular por ser uma forma de equilibrar um sistema ou uma política pública pautada em normas e diretrizes, não significa em si que haja problemáticas. Com a regulação apresentando-se como constituinte tanto de um projeto liberal quanto um democrático popular, tende a manifestar-se nas ações dos atores escolares com oscilações entre os projetos (MELO, 2012).

\section{Notas finais}

Por fim, podemos sinalizar que, ainda no âmbito nacional, a política de livro didático se manifesta em forma de múltiplas regulações. Se ela almeja difundir o pensamento político-pedagógico hegemônico e convergir a prática dos docentes a esta mesma concepção, concomitantemente, pela regulação busca garantir a qualidade dos materiais didáticos. O mecanismo utilizado para tanto foi a avaliação realizada por uma comissão de especialistas que elucida o direcionamento e intencionalidades da política, isto é, delega a produção para 
o âmbito privado. Há tensões em torno de operacionalizar uma política pública dessa maneira, pois há uma imbricação entre o público e o privado. Uma crítica a esse modelo é por favorecer a constituição de um oligopólio nas editoras e consequentes homogeneizações de conteúdos. Por outro lado, no seio da cultura escolar, os professores se apropriam dessa política, desdobrando-se em ações diversificadas de adesão ou resistência. A política de livro didático ganhou vigor com a avaliação das obras didáticas ao contribuir para diminuir os problemas com erros conceituais e manifestações preconceituosas contra os grupos minoritários, todavia não significa que findou as tensões sobre essas questões.

\section{Referências Bibliográficas}

ABRALE. O diálogo ABRALE - MEC: mais uma rodada. Informativo n³4, novembro. 2009. Disponível em: <www.abralelivroeducativo.org.br> Acesso em: 21 agosto 2011.

BARROSO, J. O Estado, a educação e a regulação das políticas públicas. Educação e Sociedade, Campinas, v. 26, n. 92, 2005.

BEZERRA, H. G; LUCA, T. R. Em busca da qualidade - PNLD História - 1996-2004. In: SPOSITO, M. E. B. (org.) Livros didáticos de Geografia e História: avaliação e pesquisa. São Paulo: Cultura Acadêmica, 2006.

BRASIL. Definição de critérios para avaliação dos livros didáticos: português, matemática, estudos sociais e ciências $1^{\circ}$ a $4^{\circ}$ séries. - Brasília: FAE, 1994.

. Plano Diretor da Reforma do Estado. Ministério da Administração Federal e da Reforma do Estado.

Brasília: Presidência da República, Imprensa Oficial, novembro, 1995.

FERREIRA, A. B. de H. O Novo Dicionário Aurélio da Língua Portuguesa. 3. ed. (edição eletrônica). Rio de janeiro: Ed. Positivo, 2010.

GRAMSCI, A. Concepção dialética da história. 10. ed. Rio de janeiro: Civilização Brasileira, 1995.

MELO, F. G. Política do livro didático para o ensino médio: fundamentos e práticas. 161 f. Dissertação (Mestrado em educação) - Faculdade de Educação, Universidade de Brasília, Brasília, 2012.

MIRANDA, S. R.; LUCA, T. R. O livro didático de história hoje: um panorama a partir do PNLD. Revista Brasileira de História. São Paulo, v. 24, n. 48, 2004.

NOGUEIRA, M. A. Gramsci e os desafios de uma política democrática de esquerda. In: AGGIO, A. (Org.). Gramsci: a vitalidade de um pensamento. São Paulo: Fundação Editora da UNESP, 1998.

PEREIRA, P. A. P. Estado, regulação social e controle democrático. In: (Orgs.) PEREIRA, P. A. P.; BRAVO, M. I. S. Política social e democracia. 4. ed. São Paulo: Cortez; Rio de Janeiro: UERJ, 2008.

SEMERARO, G. Gramsci e a sociedade civil: cultura e educação para a democracia. Petrópolis, RJ: Vozes, 1999. SOUZA, P. R. A revolução gerenciada: educação no Brasil (1995 - 2002). São Paulo: Prentice Hall, 2005.

Recebido em Janeiro de 2013 Aprovado em Junho de 2013 